\title{
Interleukin gene expression in broiler chickens infected by different Escherichia coli serotypes
}

\author{
Reham Elnagar, Rasha Elkenany (iD) and Gamal Younis (D) \\ Department of Bacteriology, Mycology, and Immunology, Faculty of Veterinary Medicine, Mansoura University, \\ Mansoura 35516, Egypt. \\ Corresponding author: Reham Elnagar, e-mail: drrehamalaa1@gmail.com \\ Co-authors: RaE: dr_rashavet22@yahoo.com, GY: gamalyounis_2006@yahoo.com \\ Received: 27-05-2021, Accepted: 13-09-2021, Published online: 24-10-2021
}

doi: www.doi.org/10.14202/vetworld.2021.2727-2734 How to cite this article: Elnagar R, Elkenany R, Younis G (2021) Interleukin gene expression in broiler chickens infected by different Escherichia coli serotypes, Veterinary World, 14(10): 2727-2734.

\begin{abstract}
Background and Aim: Escherichia coli is the cause of avian colibacillosis, a significant threat to the poultry industry and public health. Thus, this study investigated the prevalence of $E$. coli in diseased chicken broilers, pathological effects of these bacteria, and interleukin (IL) gene expression of different serotypes of E. coli (O78, O26, O44, and O55) on experimentally infected chickens.

Materials and Methods: A total of 295 organ samples (liver, lungs, heart, and spleen) from 59 diseased broiler chickens were used for conventional identification of $E$. coli. Chickens were orally infected with one of the following $E$. coli serotypes $(\mathrm{O} 78, \mathrm{O} 26, \mathrm{O} 44$, or O55) and examined for clinical signs, mortality, macroscopic and microscopic lesions, and IL gene expression using real-time quantitative polymerase chain reaction.

Results: E. coli was isolated from 53.2\% of broiler chicken organs with a high prevalence in lungs (26.1\%). The most prevalent serotypes were $\mathrm{O} 78, \mathrm{O} 26, \mathrm{O} 44, \mathrm{O} 55, \mathrm{O} 157$, and $\mathrm{O} 127$ prevalence of 27.8, 22.2, 16.7, 16.7, 5.6, and 5.6\%, respectively. In the experimental design, five groups (G1-G5) of birds were established. G1 served as the negative control group, while G2-G5 were challenged orally with E. coli O78, O26, O55, or O44, respectively. Chickens infected with E. coli $\mathrm{O} 78$ or $\mathrm{O} 26$ showed significant clinical signs in comparison to the other infected birds. Mortality (13.3\%) was only observed in birds infected with E. coli O78. Necropsy of dead birds after E. coli O78 infection showed pericarditis, enteritis, airsacculitis, and liver and lung congestion. More severe histopathological changes were observed in intestines, spleen, liver, and lung from chickens infected with either E. coli $\mathrm{O} 78$ or $\mathrm{O} 26$ than for birds infected with other serotypes. On the $2^{\text {nd }}$ day post-infection, E. coli challenge, particularly with E. coli O78, displayed significantly upregulated levels of ileal IL-6 and IL-8, but ileal IL-10 level tended to be downregulated in comparison to the control group.
\end{abstract}

Conclusion: This study assessed the application of cytokines as therapeutic agents against infectious diseases, particularly colibacillosis.

Keywords: broiler chicken, Escherichia coli, experimental infection, histopathology, interleukins.

\section{Introduction}

Escherichia coli (E. coli) is a typical microorganism in chicken intestinal tracts and trachea to a lesser degree [1]. Even common "non-pathogenic" strains of $E$. coli cause infection in animals, humans, birds, and weakened or immunocompromised hosts or when gastrointestinal barriers are breached. Further, some strains of $E$. coli invade the body and cause avian colibacillosis, a fatal systemic disease [2]. Signs of colibacillosis in poultry include infection of yolk sacs, omphalitis, hepatitis, pericarditis, septicemia, polyserositis, enteritis, cellulitis, respiratory tract infection, and salpingitis [3]. Poultry produces its immune cells and antibodies to provide protection during disease recovery [4].

Copyright: Elnagar, et al. Open Access. This article is distributed under the terms of the Creative Commons Attribution 4.0 International License (http://creativecommons.org/licenses/ by/4.0/), which permits unrestricted use, distribution, and reproduction in any medium, provided you give appropriate credit to the original author(s) and the source, provide a link to the Creative Commons license, and indicate if changes were made. The Creative Commons Public Domain Dedication waiver (http:// creativecommons.org/publicdomain/zero/1.0/) applies to the data made available in this article, unless otherwise stated.
E. coli displays molecular patterns, such as lipopolysaccharides (LPS) and flagellin, on its surface that interacts with toll-like receptors on the surface of macrophage, resulting in the secretion of interleukins (IL-1, IL-6, and IL-8) [5-7]. ILs are polypeptides produced by cells involved in immune and inflammatory responses. ILs activate and modulate other cells and tissues [8]. ILs produced by birds are poorly understood in terms of structure and function. However, recent progress in the field of avian immunology and genetics now recognizes a variety of ILs, mostly in chickens. Relatively few recombinant cytokines or monoclonal antibodies against avian cytokines have been produced, but available technologies, such as real-time quantitative polymerase chain reaction (PCR), allow quantification of messenger RNA expression from cytokine genes without the use of proteins or antibodies [9]. These tools open a whole new world of possibilities for determining the levels of ILs in illnesses, leading to a better understanding of pathogenesis and immune mechanisms. ILs also show a potential for controlling avian infectious diseases and are being examined as new curative agents. 
ILs may also serve as vaccine adjuvants, activating the immune system to encourage an effective defense response [9].

ILs, for example, IL-6, are secreted proteins involved in recruiting and controlling cells in both natural and acquired immunities. Such cytokines are needed for successful host immune responses to pathogens. Chicken IL-6 and its role in pro-inflammatory response are confirmed [10]. IL-6 aids short-term protection against infection or damage by alerting the immune system to the source of inflammation. However, illness arises from improper control of this molecule. Pro-inflammatory cytokines, such as IL-6, control the immune response by stimulating the proliferation and differentiation of leukocytes that kill pathogens [11]. The pro-inflammatory chemokine, IL-8, is a chemoattractant, drawing heterophils to the site of infection and triggering a fast local inflammatory reaction [12]. IL-8 is known for chemotactic activity toward heterophils and macrophages in chickens [13]. Further, macrophage activation stimulates the secretion of the crucial anti-inflammatory cytokine IL-10 that keeps the immune system balanced by suppressing excessive pro-inflammatory cytokine production [14]. IL-10 acts as an inflammation feedback factor, allowing modulation of the immune response [15]. IL-10 promotes Th2-like immune responses, primarily through suppressing Th1 and pro-inflammatory cytokines [16]. These anti-inflammatory properties, including inhibition of macrophage function, can make the host more susceptible to bacterial infections.

A study by Li et al. [17] reported identification and virulence of $E$. coli; however, limited research concentrates on the interaction of $E$. coli, particularly E. coli serotypes $\mathrm{O} 26$ and O44, with host innate immune response. Consequently, the primary goal of this research was the assessment of pathological and immunological influences of different $E$. coli serotypes in broiler chickens. The current study was designed to (1) determine $E$. coli prevalence in diseased broiler chickens; (2) describe impacts of infection by different serotypes of $E$. coli clinical signs, mortalities, macroscopic lesions, and histopathology; (3) and identify the effects of infection by different serotypes on IL gene expression (IL-6, IL-8, and IL-10) in broiler chickens using reverse transcription-quantitative PCR (RT-qPCR).

\section{Materials and Methods}

Ethical approval

Animal Experiments and Ethics Committee, Faculty of Veterinary Medicine, Mansoura University approved all protocols and humane euthanasia (physical method).

\section{Sample collection, study period, and location}

A total of 295 organ samples (liver, lungs, heart, and spleen) from fifty-nine 21-50-day-old broiler chickens were separately collected in the period from April to October 2019. All chickens displayed signs of disease and were obtained from 11 poultry farms situated in various geographic areas in Dakahlia and Sharqia Governorates in Egypt. The chickens exhibited diarrhea, loss of appetite, coughing, and sneezing. Ascites, pericarditis, perihepatitis, airsacculitis, and peritonitis were the most common lesions observed during necropsy. Samples were separately collected in sterile polyethylene bags, placed immediately on ice, and transferred to the laboratory for bacteriological examination.

\section{Isolation and identification of $E$. coli}

A loopful from each organ was cultured on MacConkey's agar (Oxoid, UK) plates incubated aerobically at $37^{\circ} \mathrm{C}$ for $24 \mathrm{~h}$. Suspected pink colonies were picked up, streaked, and incubated overnight at $37^{\circ} \mathrm{C}$ on eosin methylene blue (EMB) agar (Oxoid). Biochemical tests, such as catalase, oxidase, urease, methyl red, Voges-Proskauer, citrate utilization, indole, and triple sugar iron agar, were used to identify suspected E. coli colonies [18]. Slide agglutination with polyvalent and monovalent fast diagnostic sets of E. coli antisera (Denka Seiken Co., Ltd., Japan) was used to identify serotypes of $E$. coli isolates [19].

\section{Experimental design}

\section{Preparation of E. coli inocula}

E. coli serotypes $\mathrm{O} 78, \mathrm{O} 26, \mathrm{O} 55$, and $\mathrm{O} 44$ obtained from local cases of avian colibacillosis as described above were enriched in trypticase soy broth (Oxoid) and incubated at $37^{\circ} \mathrm{C}$ for $24 \mathrm{~h}$. The surface spread method was used to determine viable cells per $\mathrm{mL}$ of trypticase soy broth [20]. E. coli suspensions containing $10^{9} \mathrm{CFU} / \mathrm{mL}$ were prepared as previously described by Ateya et al. [21]. Infection with E. coli serotypes was achieved by oral administration of $0.5 \mathrm{~mL}$ of bacterial suspension to 7-day-old chicks using a syringe attached to a polyethylene tube. Birds were given a similar amount of sterile phosphate buffer saline as a negative control.

\section{Experimental chicks}

The experiment used 75 healthy Hubbard broiler chicks obtained from a commercial hatchery when 1 day old. Broiler chicks were divided into five groups of 15 birds at random. All birds were supplied with a balanced commercial starter till day 14 throughout the experiment. Fresh and clean drinking water was supplied ad libitum. Chicks were housed in a clean well-ventilated, previously fumigated room. The first group (G1) served as a standard negative control group, the second group (G2) was infected by E. coli O78, the third group (G3) by E. coli O26, the fourth group (G4) by E. coli O55, and the fifth group (G5) by E. coli $\mathrm{O} 44$.

\section{Clinical symptoms, mortality, and macroscopic lesions}

Birds in each group were monitored twice a day for clinical symptoms and mortality. E. coli 
colonization in visceral organs and gross lesions was by gathering, necropsying, and taking specimens of dead and sacrificed birds.

\section{E. coli reisolating from internal organs}

Two chickens per group were randomly selected and sacrificed on days 7 and 14 post-inoculation for reisolating $E$. coli from visceral organs. Liver, spleen, lungs, and cecum samples from these birds were streaked on EMB agar and incubated at $37^{\circ} \mathrm{C}$ for 18-24 h. Suspected E. coli colonies were identified using morphological, biochemical, and serological methods, as mentioned before.

\section{Histopathological examination}

On day 14, samples from liver, spleen, lung, intestine, and heart were fixed in $10 \%$ neutral buffered formalin. Hematoxylin and eosin stained $5 \mu \mathrm{m}$ thick paraffin sections were examined microscopically [22].

\section{Collection of ileum sample}

On day 2, five birds from each group were sacrificed at random for collecting ileal samples. Ileal specimens were aseptically washed in phosphate-buffered saline, snap frozen in RNA later (Qiagen, Germany) solution, and stored at $-80^{\circ} \mathrm{C}$ for later quantification of gene expression.

\section{RT-qPCR}

IL gene expression (IL-6, IL-8, and IL-10) in ileal tissue was quantified using RNA extraction used an RNeasy Mini Kit (Catalogue no.74104, Qiagen). A $30 \mathrm{mg}$ of tissue sample was homogenized and processed as described by the manufacturer. IL-6, IL-8, and IL-10 mRNA were amplified and quantified using a real-time PCR machine (Stratagene MX3005P, Agilent Technologies Company, USA). Primer sequences are listed in Table-1 $[23,24]$. The housekeeping gene 28S rRNA was used as a constitutive control for normalization. The reaction mixture volume was $25 \mu \mathrm{L}$ made up with $12.5 \mu \mathrm{L} 2 \mathrm{x}$ QuantiTect Probe RT-PCR Master Mix (catalog No.204443, Qiagen), $0.5 \mu \mathrm{L}$ of $20 \mathrm{pmol}$ solution of each primer, $0.125 \mu \mathrm{L}$ probe $(30 \mathrm{pmol}), 0.25 \mu \mathrm{L}$
QuantiTect RT Mix (RevertAid Reverse Transcriptase) (Qiagen), 8.125 $\mu \mathrm{L}$ RNase-free water (Sedico, Egypt), and $3 \mu \mathrm{L}$ template RNA. The real-time PCR cycling conditions were reverse transcription $\left(50^{\circ} \mathrm{C}, 30 \mathrm{~min}\right)$, primary denaturation $\left(94^{\circ} \mathrm{C}, 10 \mathrm{~min}\right)$, and then amplification (40 cycles) with secondary denaturation $\left(94^{\circ} \mathrm{C}, 15 \mathrm{~s}\right)$, annealing, and extension $\left(60^{\circ} \mathrm{C}, 1 \mathrm{~min}\right)$. Amplification curves and $\mathrm{Ct}$ values were determined using Stratagene MX3005P software, Agilent Technologies Company). The Ct value of each sample was compared with the positive control as described for the " $\Delta \Delta \mathrm{CT}$ " method [25].

\section{Statistical analysis}

Data were analyzed using one-way analysis of variance with the statistical program SPSS, version 17.0 (SPSS Inc., Chicago, IL, USA). Means of ileal gene expression levels were compared at $p<0.05$ using Tukey's test for statistical significance.

\section{Results}

\section{E. coli prevalence in sick broiler chicken}

E. coli was isolated from 32 of 59 broiler chickens $(54.2 \%)$. A total of $157(53.2 \%)$ isolates of pathogenic E. coli were obtained from 295 samples. These isolates were identified morphologically and biochemically from chicken organs. The highest incidence of E. coli was detected in lungs 41/157 (26.1\%), followed by liver 40/157 (25.5\%), heart 33/157 (21.1\%), and spleen 24/157 (15.3\%). Serological identification of 18 biochemically identified $E$. coli strains showed six serotypes (Table-2). E. coli serotype O78 was predominant $(27.8 \%)$, followed by $\mathrm{O} 26(22.2 \%)$, O44 and O55 (16.7\% each), and O157 and O127 (5.6\% each).

\section{Experimental infection results}

\section{Clinical signs, mortality, and macroscopic lesions}

All broiler chickens inoculated with $E$. coli serotypes O78, O26, O55, or O44 were inspected. Ruffled feathers, inappetence, respiratory manifestations, sitting on hocks, and diarrhea (yellow to whitish) were the

Table-1: Oligonucleotide primers and probes used in real-time PCR.

\begin{tabular}{|c|c|c|}
\hline \multirow[t]{2}{*}{ Gene } & Primer sequence & \multirow[t]{2}{*}{ Reference } \\
\hline & $\left(5^{\prime}-3^{\prime}\right)$ & \\
\hline \multirow[t]{3}{*}{$I L-6$} & GCTCGCCGGCTTCGA & \\
\hline & GGTAGGTCTGAAAGGCGAACAG & [23] \\
\hline & $\begin{array}{l}\text { (FAM) AGGAGAAATGCCTGACGAAGCTCTCCA } \\
\text { (TAMRA) }\end{array}$ & \\
\hline \multirow[t]{3}{*}{$28 S$ rRNA } & GGCGAAGCCAGAGGAAACT & \\
\hline & GACGACCGATTTGCACGTC & \\
\hline & (FAM) AGGACCGCTACGGACCTCCACCA (TAMRA) & \\
\hline \multirow[t]{3}{*}{$I L-8$} & GCCCTCCTCCTGGTITCAG & \\
\hline & TGGCACCGCAGCTCATT & \\
\hline & $\begin{array}{l}\text { (FAM) TCTTTACCAGCGTCCTACCTTGCGACA } \\
\text { (TAMRA) }\end{array}$ & \\
\hline \multirow[t]{3}{*}{$I L-10$} & CATGCTGCTGGGCCTGAA & {$[24]$} \\
\hline & CGTCTCCTTGATCTGCTTGATG & \\
\hline & (FAM) CGACGATGCGGCGCTGTCA (TAMRA) & \\
\hline
\end{tabular}

PCR $=$ Polymerase chain reaction 
most common signs observed in experimentally infected birds. Clinical signs were more severe in birds in G2 (O78 infected) and $\mathrm{G} 3$ (O26 infected) than in birds in $\mathrm{G} 4$ (O55 infected) and G5 (O44 infected). Signs observed in birds in $\mathrm{G} 2$ were more severe than signs recorded from other birds. Mortality was only observed in G2 birds $(13.3 \% ; 2 / 15)$; no mortality was recorded in other chickens throughout the experimental period. Pericarditis, enteritis, airsacculitis (cloudy to fibrinous exudate in air sacs), and liver and lung congestion were seen during necropsy of dead birds in G2. No clinical symptoms or deaths were observed in the control birds (G1).

\section{E. coli reisolation from internal organs}

Recovery of $E$. coli from internal organs of different groups was performed. E. coli strains were reisolated from visceral organs (liver, spleen, lung, and cecum) of chickens in all experimentally infected birds (G2-G5) on days 7 and 14. No E. coli was recovered from any control birds.

\section{Histopathological findings of internal organs}

Histopathological lesions observed in livers of G2 chickens were inflammation, interstitial hemorrhages, portal tract mononuclear cell infiltration, congestion, and focal feathery degeneration (Figure-1b). Livers from G3 birds showed similar lesions but with more hemorrhages and less inflammation (Figure-1c) in comparison to control (Figure-1a). Lesions in hearts from G2 and G3 were mild thickening of pericardium, degeneration of myocardium, but no significant inflammatory cell infiltration (Figure-2b) in comparison to control (Figure-2a). Congestion, focal necrosis, and dilated sinusoids with inflammatory cells were observed in the spleen in birds in G2 and G3 (Figure-3b) in comparison to control (Figure-3a). In the intestine, sloughing of intestinal epithelium and inflammatory cell infiltration was severe in chickens in G2 and G3 (Figure-4b) but less serious in birds in G4 in comparison to control (Figure-4a). In the lungs, severe congestion, hemorrhage, and moderate inflammatory cellular infiltration were observed in birds in G2, G3, and G5 (Figure-5b) G4 in comparison to control (Figure-5a).

E. coli infection upregulates expression of $I L-6, I L-8$, and $I L-10$

Relative quantitative RT-qPCR was used to assess relative gene expression of pro-inflammatory

Table-2: Serotyping of $E$. coli isolates from diseased chicken $(n=18)$.

\begin{tabular}{llcc}
\hline Serotype & Types of samples & $\begin{array}{c}\text { No. of } \\
\text { isolates }\end{array}$ & \\
\hline O78 & Lungs $(n=2)$, liver, & 5 & 27.8 \\
& heart, spleen & & \\
O44:K74 & Spleen, heart, liver & 3 & 16.7 \\
O55:K59 & Heart, lung $(n=2)$ & 3 & 16.7 \\
O26:K60 & Lung, heart $(n=2)$, spleen & 4 & 22.2 \\
O157:K- & Lung & 1 & 5.6 \\
O127 & Liver & 1 & 5.6 \\
\hline
\end{tabular}

E. coli=Escherichia coli cytokines (IL-6, IL-8, and IL-10) in the ileum of birds following $E$. coli challenge on 2 days after infection. In contrast to the control group, $E$. coli challenge elevated mRNA expression of ileal IL- 6 and IL- 8 but appeared to lower ileal IL-10 expression (Figure-6). The highest significant elevation in mRNA expression of IL-6 was recorded in birds from G2. Other chickens (G1, G3, G4, and G5) showed significant downregulation in ileal IL-6 $(\mathrm{p}<0.05)$. IL-6 gene expression in G2 showed the greatest effect, a 9.5-fold increase over controls. The smallest effect was observed in birds from G4, a 3-fold change (Figure-6). Chickens from G2 also showed higher ileal IL-8 levels than birds from G3 and G1. However, G2 ileal IL-10 level was significantly lower.

\section{Discussion}

Primary infection in the respiratory tract can be caused by pathogenic $E$. coli. Such infection may result in systemic infection and appearance of a disease known as colibacillosis in chickens [26]. Lower hatching rates, egg production, and inhibition of growth along with increased mortality occur due to colibacillosis, which is currently the main cause of economic losses in the poultry industry worldwide [27]. The incidence of $E$. coli isolated from samples of Egyptian broiler chickens that showed clinical signs of colibacillosis was $53.2 \%$. Similarly, the previous studies showed a high incidence of $E$. coli $(52.3 \%, 53.8 \%$, and $57.3 \%)$ at different localities in Egypt [28-30]. Furthermore, $E$. coli was isolated from $53.4 \%$ of the internal organs of ill broiler chickens in Jordan [31]. Conversely, a lower incidence of $E$. coli in chickens was previously reported in the range of 26.9-36.5\% [32-34]. Pilling of $E$. coli in aerosols in chicken barns allows birds to inhale $E$. coli and supports a high disease incidence in chicken broilers.

$E$. coli was found in a variety of internal organs, with high rates of isolation from lungs $(26.1 \%)$ and liver $(25.5 \%)$ [33,35]. The isolation of E. coli from several organs is a sign of intestinal $E$. coli invasion. High isolation rates from lungs and liver may be attributed to an initial respiratory tract infection that spreads to other internal organs [36].

The serotyping analysis that distinguishes pathogenic strains based on surface antigens is a more accurate identification method. Serogroup $\mathrm{O}$ is one basic diagnostic for classifying pathogenic $E$. coli strains. Serological identification showed that serotype $078(27.8 \%)$ was predominant followed by O26 (22.2\%) than other serotypes. O78 was the dominant serotype in Egypt among other serogroups (O1, $\mathrm{O} 26, \mathrm{O} 2, \mathrm{O} 127, \mathrm{O} 91$, and O153) isolated from broiler chicken viscera [28]. Broiler chickens infected with E. coli in China and Jordan showed that $\mathrm{O} 78$ was the most prevalent serotype [31,37]. O26 was identified in the present investigation from chickens suffering from septicemia. This serogroup is not common in chickens but may be transmitted from other animals 


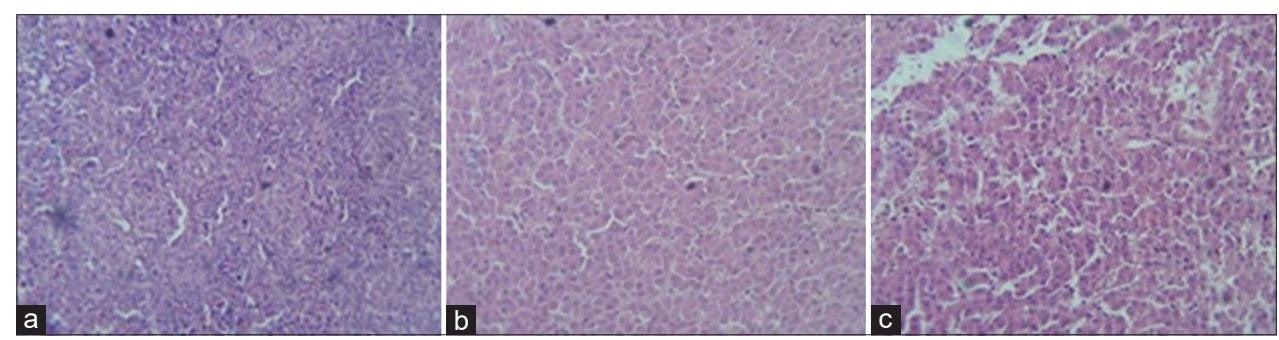

Figure-1: Photomicrograph of sections from liver of broiler chicks on 7 days post-infection with Escherichia coli stained with H\&E. (a) Histological picture of liver shows normal picture in G1 (control group); (b) interstitial, hemorrhages, portal tract mononuclear cell infiltration, congestion, and focal feathery degeneration in G2; (c) severe hemorrhages, less inflammation, interstitial hemorrhages, portal tract mononuclear cell infiltration, congestion, and focal feathery degeneration in G3.

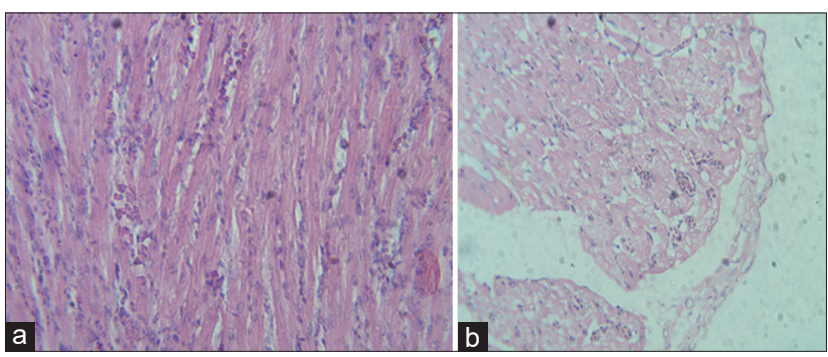

Figure-2: Photomicrograph of sections from heart of broiler chicks on 7 days post-infection with Escherichia coli stained with $\mathrm{H} \& \mathrm{E}$. (a) Histological picture of heart shows normal picture in G1 (control group); (b) mild thickening of pericardium, degeneration of myocardium, and no significant inflammatory cell infiltrate in G2 and G3.
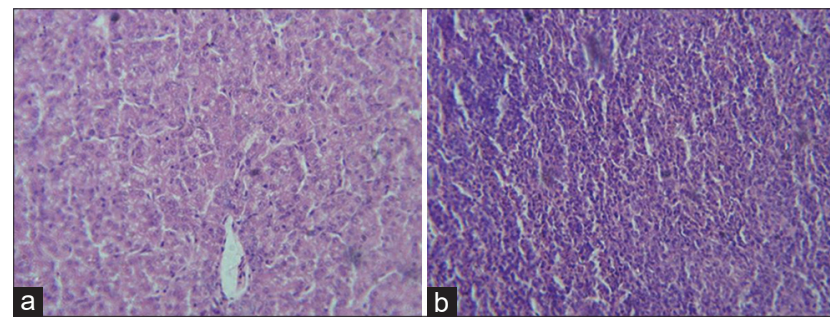

Figure-3: Photomicrograph of section from spleen of broiler chicks on 7 days post-infection with Escherichia coli stained with $\mathrm{H} \& \mathrm{E}$. (a) Histological picture of spleen shows normal picture in G1 (control group); (b) congestion, focal necrosis, and dilated sinusoids by inflammatory cells infiltrate in G2 and G3.

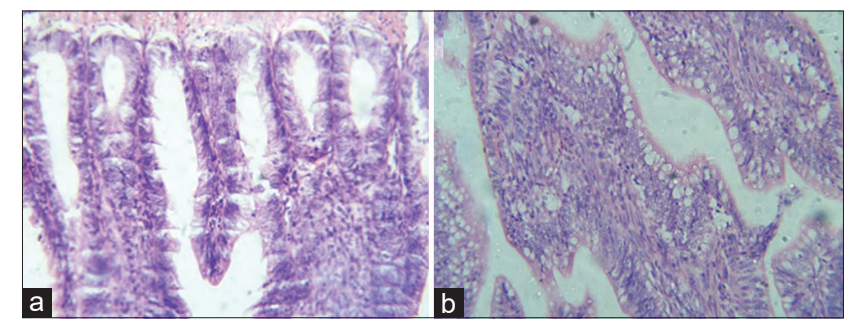

Figure-4: Photomicrograph of sections from intestine of broiler chicks on 7 days post-infection with Escherichia coli stained with $\mathrm{H} \& \mathrm{E}$. (a) Histological picture of heart shows normal picture in G1 (control group); (b) sloughing of epithelium and inflammatory cell infiltration in G2 and G3.

to chickens raised nearby. Thus, raising chickens at a distance from other animals may be important for preventing the transmission of $E$. coli isolates among livestock.

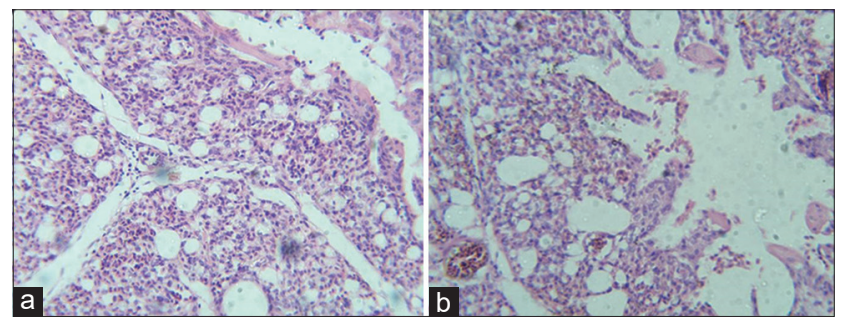

Figure-5: Photomicrograph of sections from lung of broiler chicks on 7 days post-infection with Escherichia coli stained with $\mathrm{H} \& \mathrm{E}$. (a) Histological picture of lung shows normal picture in G1 (control group); (b) severe congestion, hemorrhages, and inflammatory cellular infiltrate in G2, G3, and G5.

Ruffled feathers, decreased appetite, respiratory symptoms, sitting on hocks, and yellow to whitish diarrhea were the most commonly noted signs in experimentally infected birds. In birds infected with E. coli $\mathrm{O} 78$ and $\mathrm{O} 26$ (G2 and G3), clinical manifestations were more severe, with $13.3 \%$ mortality. This result is consistent with a previous study [38] that reported mouth breathing, sneezing, ruffled feathers, weights loss, diarrhea, loss of appetite, diarrhea, and mortality (30\%) in chickens infected with E. coli $\mathrm{O} 78$. Another study indicated depression with whitish diarrhea in broiler chickens infected experimentally with E. coli $\mathrm{O} 78[21,39]$. Birds exhibited a $12.82 \%$ mortality after $48 \mathrm{~h}$ among birds challenged with $E$. coli. Further, postmortem examination of the dead birds in chickens infected with E. coli O78 (G2) in the present study showed pericarditis, enteritis, airsacculitis, and liver and lung congestion. A similar investigation also reported congestion in different organs, as well as fibrin accumulation in the liver (bread and butter appearance) and heart [40].

Histopathological lesions varied from mild to severe, reflecting virulence and pathogenicity. Chickens infected with E. coli $\mathrm{O} 78$ or O26 displayed more severe histopathological changes in the liver, spleen, intestine, and lung samples than birds infected with other serotypes. In contrast, only mild lesions were exhibited in heart tissues. Some findings may be due to infection-induced immunosuppression and stress [41]. A previous study by Shah et al. [40] also reported fibrinous pericarditis, myocarditis, fibrinous perihepatitis, hepatitis, fatty changes in hepatocytes, 


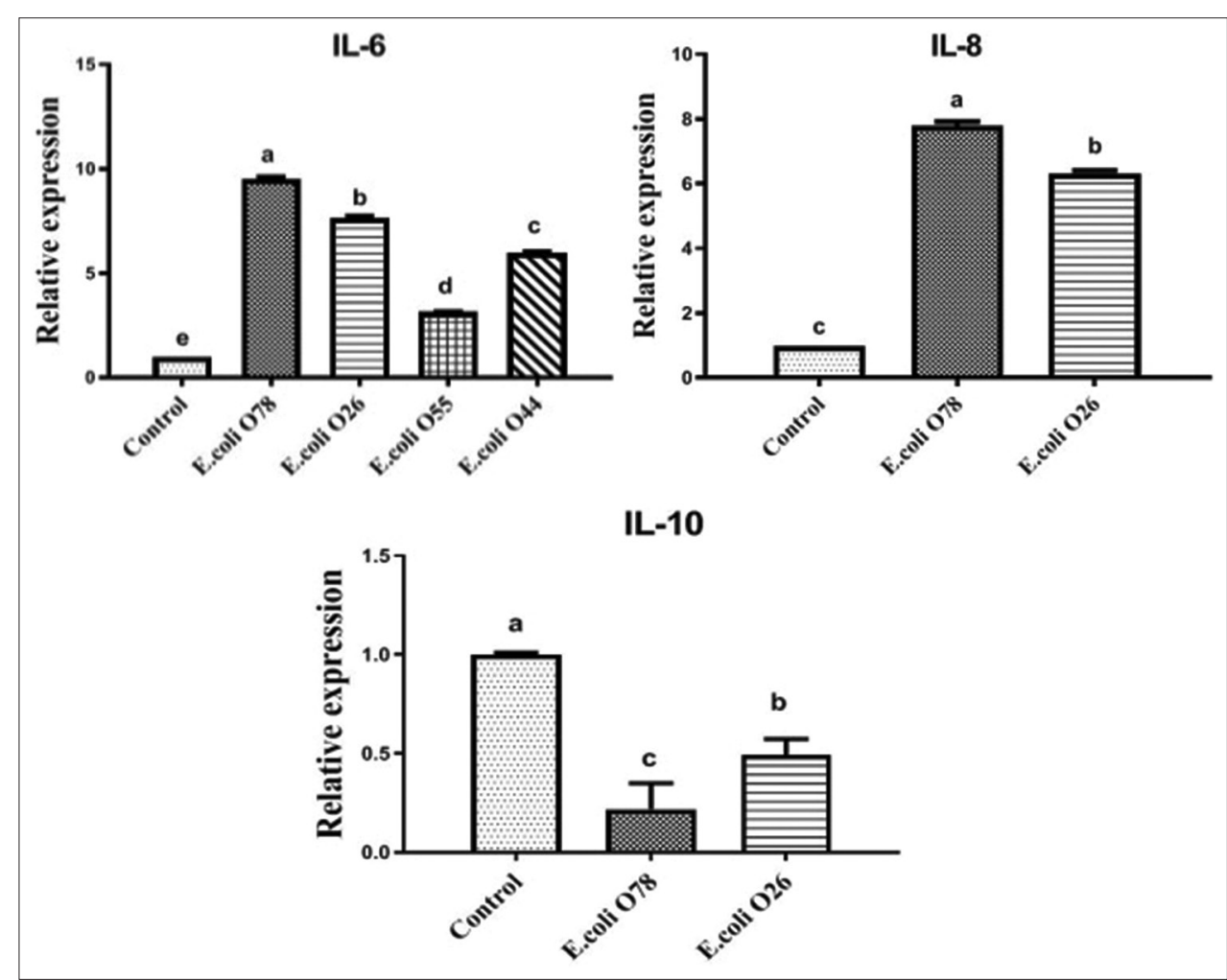

Figure-6: Reverse transcription-polymerase chain reaction analyses for the expression of pro-inflammatory cytokine (IL6, IL-8, and IL-10) in the ileum of birds challenged with different serotypes of Escherichia coli $(078,026,055$, and O44). Data were expressed as mean \pm standard error. The different letters indicate a significant difference $(p<0.05)$ between experimental groups.

interstitial pneumonia, necrosis, and depletion of lymphocytes in spleen, consistent with these findings. Finally, inflammation, congestion, and degenerative changes in the liver, heart, splenic cells, and intestine with sloughing of epithelium were reported [42].

ILs are extracellular signaling molecules that transmit information between cells for modulating immune responses as part of both natural and adaptive immunities [8]. Relative RT-qPCR is the most accurate method for the detection and quantification of gene expression in cells and tissues for low abundance mRNA due to its high sensitivity, good reproducibility, and wide quantification range [43]. Gene expression in this study showed a relationship between pro-inflammatory cytokine levels (IL-6, IL-8, and IL10) and the challenge induced by various E. coli serotypes in broiler chickens. Upregulation of mRNA expression of ileal IL-6 and IL- 8 genes, but downregulation of ileal IL-10 expression followed $E$. coli challenge. These changes occurred early after infection (day 2), and IL-6 and IL-8 likely participate in host immune response to pathogens [41,44]. Both cytokines are critical for initiating an acute-phase immune response against invading pathogens and triggering a variety of immune cells, such as $\mathrm{T}$ cells and macrophages [9]. A significant increase in $I L-6$ and $I L-8$ gene expression in the ileum of birds infected with $E$. coli $\mathrm{O} 78(\mathrm{G} 2)$ was seen compared to other chickens. Upregulation may be a result of greater pathogenicity of E. coli serotype O78 compared to other examined serotypes. Thus, E. coli O78 might overstimulate the immune system to a greater extent than other tested serotypes. Inoculation with $E$. coli induced secretion of pro-inflammatory cytokines IL-1b, IL-6, and IL-8, especially in splenic cells and pulmonary tissue $[21,45,46]$. Overall, small increases in pro-inflammatory cytokines may reflect the age of chicks. Natural resistance to infection with E. coli had developed in chicks by the age of 3 weeks [47].

Further, phagocytic cells of the natural immune system secrete IL-10 due to E. coli infection. In this study, anti-inflammatory cytokine $(I L-10)$ gene expression was reduced after exposure to E. coli $\mathrm{O} 78$ or O26 that was compatible to previous studies [21,48]. Expression of IL-10 was suppressed after exposure to LPS $[49,50]$. When broilers were nourished with mannanoligosaccharide and then challenged with E. coli, ileal IL-10 expression was higher than when they were challenged with E. coli only [46]. Furthermore, in chickens infected with $E$. coli, a large elevation in liver IL-10 occurred [51]. Differences in gene expression among studies could be due to different challenge approaches and measuring methods.

\section{Conclusion}

This is the first study to demonstrate the impact of avian E. coli serotypes $\mathrm{O} 44$ and $\mathrm{O} 26$ on the pathological status and IL gene expression in broiler chickens. A high prevalence of $E$. coli in broiler chicken that might be associated with major economic losses 
was found. Experimental infection with different serotypes of $E$. coli connected adverse effects with a shift in the equilibrium of cytokines. IL-6 and IL-8 are upregulated and IL-10 downregulated. This imbalance causes inflammation-induced damage in several internal organs. Further studies might clarify the utility of cytokines as therapeutic agents against infectious diseases, particularly colibacillosis. In addition, the application of control and preventive measures is highly recommended for poultry farms to limit bacterial diseases, such as colibacillosis, that are associated with major economic losses and public health hazards.

\section{Authors' Contributions}

GY and RaE: Designed the experiment, supervised the study, and drafted the manuscript. RE: Collected the samples and carried out the practical part. All authors read and approved the final manuscript.

\section{Acknowledgments}

The authors are thankful to Department of Bacteriology, Mycology, and Immunology, Faculty of Veterinary Medicine, Mansoura University, Egypt, for providing the necessary facilities. The authors did not receive any funds for this study.

\section{Competing Interests} interests.

The authors declare that they have no competing

\section{Publisher's Note}

Veterinary World remains neutral with regard to jurisdictional claims in published institutional affiliation.

\section{References}

1. Kaper, J.B., Nataro, J.P. and Mobley, H.L. (2004) Pathogenic Escherichia coli. Nat. Rev. Microbiol., 2(2): 123-140.

2. Nakazato, G., Campos, T.A.D., Stehling, E.G., Brocchi, M. and Silveira, W.D.D. (2009) Virulence factors of avian pathogenic Escherichia coli (APEC). Pesqui. Vet. Bras., 29(7): 479-486.

3. Nolan, L.K., Barnes, H.J., Vaillancourt, J.P., Abdul-Aziz, T. and Logue, C.M. (2013) Colibacillosis. In: Swayne, D.E., Glisson, J.R., McDougald, L.R., Nolan, L.K., Suarez, D.L. and Nair, V., editors. Diseases of Poultry. $13^{\text {th }}$ ed. Iowa State Press, Iowa. p751-805.

4. Janeway, C.A., Travers, P., Walport, M. and Shlomchik, M.J. (2001) Immunobiology, the Immune System in Health and Disease. Garland Science, New York.

5. Iqbal, M., Philbin, V.J. and Smith, A.L. (2005) Expression patterns of chicken toll-like receptor mRNA in tissues, immune cell subsets and cell lines. Vet. Immunol. Immunopathol., 104(1-2): 117-127.

6. Kogut, M.H., Iqbal, M., He, H., Philbin, V., Kaiser, P. and Smith, A. (2005) Expression and function of toll-like receptors in chicken heterophils. Dev. Comp. Immunol., 29(9): 791-807.

7. Zhang, M., Nii, T., Isobe, N. and Yoshimura, Y. (2012) Expression of toll-like receptors and effects of lipopolysaccharide on the expression of pro-inflammatory cytokines and chemokine in the testis and epididymis of roosters. Poult. Sci., 91(8): 1997-2003.

8. Kaiser, P. and Staheli, P. (2008) Avian cytokines and chemokines. In: Davison, F., Kaspers, B. and Schat, K.A., editors.
Avian Immunol. Elsevier, London, UK. p203.

9. Wigley, P. and Kaiser, P. (2003) Avian cytokines in health and disease. Rev. Bras. Cienc. Avic., 5(1): 1-14.

10. Kaiser, J.T., Clausen, T., Bourenkow, G.P., Bartunik, H.D., Steinbacher, S. and Huber, R. (2000) Crystal structure of a NifS-like protein from Thermotoga maritima: Implications for iron sulphur cluster assembly. J. Mol. Biol., 297(2): 451-464.

11. Rodes, L., Khan, A., Paul, A., Coussa-Charley, M., Marinescu, D., Tomaro-Duchesneau, C. and Prakash, S. (2013) Effect of probiotics Lactobacillus and Bifidobacterium on gut-derived lipopolysaccharides and inflammatory cytokines: An in vitro study using a human colonic microbiota model. J. Microbiol. Biotechnol., 23(4): 518-526.

12. Withanage, G.S.K., Kaiser, P., Wigley, P., Powers, C., Mastroeni, P., Brooks, H., Barrow, P., Smith, A., Maskell, D. and McConnell, I. (2004) Rapid expression of chemokines and proinflammatory cytokines in newly hatched chickens infected with Salmonella enterica serovar Typhimurium. Infect. Immun., 72(4): 2152-2159.

13. Poh, T.Y., Pease, J., Young, J.R., Bumstead, N. and Kaiser, P. (2008) Re-evaluation of chicken CXCR1 determines the true gene structure: CXCLi1 (K60) and CXCLi2 (CAF/ interleukin-8) are ligands for this receptor. J. Biol. Chem., 283(24): 16408-16415.

14. Corwin, E.J. (2000) Understanding cytokines Part I: Physiology and mechanism of action. Biol. Res. Nurs., 2(1): 30-40.

15. Sanjabi, S., Zenewicz, L.A., Kamanaka, M. and Flavell, R.A. (2009) Anti-inflammatory and pro-inflammatory roles of TGF- $\beta$, IL-10, and IL-22 in immunity and autoimmunity. Curr. Opin. Pharmacol., 9(4): 447-453.

16. Rothwell, L., Young, J.R., Zoorob, R., Whittaker, C.A., Hesketh, P., Archer, A., Smith, A.L. and Kaiser, P. (2004) Cloning and characterization of chicken IL-10 and its role in the immune response to Eimeria maxima. J. Immunol., 173(4): 2675-2682.

17. Li, R., Li, N., Zhang, J., Wang, Y., Liu, J., Cai, Y., Chai, T. and Wei, L. (2016) Expression of immune-related genes of ducks infected with avian pathogenic Escherichia coli (APEC). Front. Microbiol., 7: 637.

18. Quinn, P.J., Markey, B.K., Leonard, F.C., FitzPatrick, E.S., Fanning, S. and Hartigan, P.J. (2011) Veterinary Microbiology and Microbial Disease. $2^{\text {nd }}$ ed. WileyBlackwell Inc., United States.

19. Kok, T., Worswich, D. and Gowans, E. (1996) Some serological techniques for microbial and viral infections. In: Collee, J., Fraser, A., Marmion, B. and Simmons, A., editors. Practical Medical Microbiology. 14 ${ }^{\text {th }}$ ed. Churchill Livingstone, Edinburgh, UK.

20. Sadeyen, J.R., Kaiser, P., Stevens, M.P. and Dziva, F. (2014) Analysis of immune responses induced by avian pathogenic Escherichia coli infection in turkeys and their association with resistance to homologous re-challenge. Vet. Res., 45(1): 1-12?

21. Ateya, A.I., Arafat, N., Saleh, R.M., Ghanem, H.M., Naguib, D., Radwan, H.A. and Elseady, Y.Y. (2019) Intestinal gene expressions in broiler chickens infected with Escherichia coli and dietary supplemented with probiotic, acidifier and synbiotic. Vet. Res. Commun., 43(2): 131-142.

22. Wolfe, D. (2019) Tissue processing. In: Suvarna, S.K., Layton, C. and Bancroft, J.D. editors. Bancroft's Theory and Practice of Histological Techniques. Elsevier, Amsterdam, Netherlands. p73-83.

23. Suzuki, K., Okada, H., Itoh, T., Tada, T., Mase, M., Nakamura, K., Kubo, M. and Tsukamoto, K. (2009) Association of increased pathogenicity of Asian H5N1 highly pathogenic avian influenza viruses in chickens with highly efficient viral replication accompanied by early destruction of innate immune responses. J. Virol., 83(15): 7475-7486. 
24. Samy, A.A., El-Enbaawy, M.I., El-Sanousi, A.A., Abd El-Wanes, S.A., Ammar, A.M., Hikono, H. and Saito, T. (2015) In vitro assessment of differential cytokine gene expression in response to infections with Egyptian classic and variant strains of highly pathogenic $\mathrm{H} 5 \mathrm{~N} 1$ avian influenza virus. Int. J. Vet. Sci. Med., 3(1-2): 1-8.

25. Yuan, J.M., Guo, Y.M., Yang, Y. and Wang, Z.H. (2007) Characterization of fatty acid digestion of Beijing fatty and arbor acres chickens. Asian. Australas. J. Anim. Sci., 20(8): 1222-1228.

26. Dziva, F. and Stevens, M. P. (2008) Colibacillosis in poultry: Unravelling the molecular basis of virulence of avian pathogenic Escherichia coli in their natural hosts. Avian Pathol., 37(4): 355-366.

27. Zhuang, Q.Y., Wang, S.C., Li, J.P., Liu, D., Liu, S., Jiang, W.M. and Chen, J.M. (2014) A clinical survey of common avian infectious diseases in China. Avian Dis., 58(2): 297-302.

28. El-Mongy, M.A., Abd-El-Moneam, G.M., Moawad, A.A. and Mohammed, A.B.A. (2018) Serotyping and virulence genes detection in Escherichia coli isolated from broiler chickens. J. Biol. Sci., 18(1): 46-50.

29. Ali, A., AbdEl-Mawgoud, A.I., Dahshan, A.M., El-Sawah, A.A., Nasef, S.A. and Ibrahim, M. (2019) Virulence gene constellations associated with lethality in avian pathogenic $E$. coli recovered from broiler chickens. Adv. Anim. Vet. Sci., 7(12): 1076-1082.

30. Awad, A.M., El-Shall, N.A., Khalil, D.S., El-Hack, A., Mohamed, E., Swelum, A.A., Mahmoud, A.H., Ebaid, H., Komany, A., Sammour, R.H. and Sedeik, M.E. (2020) Incidence, pathotyping, and antibiotic susceptibility of avian pathogenic Escherichia coli among diseased broiler chicks. Pathogens, 9(2): 114.

31. Ibrahim, R.A., Cryer, T.L., Lafi, S.Q., Basha, E.A., Good, L. and Tarazi, Y.H. (2019) Identification of Escherichia coli from broiler chickens in Jordan, their antimicrobial resistance, gene characterization and the associated risk factors. BMC Vet. Res., 15(1): 1-16.

32. Ramadan, H., Awad, A. and Ateya, A. (2016) Detection of phenotypes, virulence genes and phylotypes of avian pathogenic and human diarrheagenic Escherichia coli in Egypt. J. Infect. Dev. Ctries., 10(6): 584-591.

33. Younis, G., Awad, A. and Mohamed, N. (2017) Phenotypic and genotypic characterization of antimicrobial susceptibility of avian pathogenic Escherichia coli isolated from broiler chickens. Vet. World, 10(10): 1167-1172.

34. Sarba, E.J., Kelbesa, K.A., Bayu, M.D., Gebremedhin, E.Z., Borena, B.M. and Teshale, A. (2019) Identification and antimicrobial susceptibility profile of Escherichia coli isolated from backyard chicken in and around ambo, Central Ethiopia. BMC Vet. Res., 15(1): 1-8.

35. Abd El Tawab, A.A., El-Hofy, F.I., Ammar, A.M., Abdel Hakeem, M. and Abdel Galil, N.M. (2016) Preliminary studies on E. coli implicated in avian colibacillosis with reference to their antibiotic resistance profiles. Benha Vet. Med. J., 30(1): 68-77.

36. Barnes, H.J. and Gross, W.B. (1999) Colibacillosis. In: Calnek, B.W., Beard, C.W., McDougald, L.M. and Saifin, Y.M., editors. Diseases of Poultry. Iowa State University Press, Ames. p131-141.

37. Jin, W.J., Zheng, Z.M., Zhang, Y.Z., Qin, A.J., Shao, H.X., Liu, Y.L., Wang, J. and Wang, Q.Q. (2008) Distribution of virulence-associated genes of avian pathogenic Escherichia coli isolates in China. Agric. Sci. China, 7(12): 1511-1515.

38. Hashem, M.A., Neamat-Allah, A.N., Hammza, H.E. and
Abou-Elnaga, H.M. (2019) Impact of dietary supplementation with Echinacea purpurea on growth performance, immunological, biochemical, and pathological finding in broiler chickens infected by pathogenic E. coli. Trop. Anim. Health Prod., 52(4): 1599-1607.

39. Fadl, S.E., El-Gammal, G.A., Sakr, O.A., Salah, A.A., Atia, A.A., Prince, A.M. and Hegazy, A.M. (2020) Impact of dietary Mannan-oligosaccharide and $\beta$-Glucan supplementation on growth, histopathology, E. coli colonization and hepatic transcripts of TNF- $\alpha$ and NF- $x$ B of broiler challenged with $E$. coli $\mathrm{O}$ 78. BMC Vet. Res., 16(1): 1-14.

40. Shah, S.A., Mir, M.S., Wani, B.M., Kamil, S.A., Goswami, P., Amin, U., Shafi, M., Rather, M.A. and Beigh, A.B. (2019) Pathological studies on avian pathogenic Escherichia coli infection in broilers. Pharm. Innov. J., 8(7): 68-73.

41. Eladl, A.H., Farag, V.M., El-Shafei, R.A., Elkenany, R.M., Elsayed, M.M., Mona, M.M., Ali, H.S. and Saif, M.A. (2019) Effect of colibacillosis on the immune response to a rabbit viral haemorrhagic disease vaccine. Vet. Microbiol., 238: 108429 .

42. Jan, A.W., Javed, M.T., Lone, S.Q., Aslam, M.S. and Javed, A. (2018) Association of six selected pathogenicity genes of Escherichia coli with gross and histopathological lesions in broiler chickens from field cases. Pak. J. Agric. Sci., 55(2): 433-440.

43. Pfaffl, M.W. and Hageleit, M. (2001) Validities of mRNA quantification using recombinant RNA and recombinant DNA external calibration curves in real-time RT-PCR. Biotechnol. Lett., 23(4): 275-282.

44. Dalrymple, S.A., Slattery, R., Aud, D.M., Krishna, M., Lucian, L.A. and Murray, R. (1996) Interleukin-6 is required for a protective immune response to systemic Escherichia coli infection. Infect. Immun., 64(8): 3231-3235.

45. Ariaans, M.P., Matthijs, M.G., van Haarlem, D., van de Haar, P., van Eck, J.H., Hensen, E.J. and Vervelde, L. (2008) The role of phagocytic cells in enhanced susceptibility of broilers to colibacillosis after infectious bronchitis virus infection. Vet. Immunol. Immunopathol., 123(3-4): 240-250.

46. Huang, L., Luo, L., Zhang, Y., Wang, Z. and Xia, Z. (2019) Effects of the dietary probiotic, Enterococcus faecium NCIMB11181, on the intestinal barrier and system immune status in Escherichia coli O78-challenged broiler chickens. Probiotics Antimicrob. Proteins, 11(3): 946-956.

47. Goren, E. (1978) Observations on experimental infection of chicks with Escherichia coli. Avian Pathol., 7(2): 213-224.

48. Wang, W., Li, Z., Han, Q., Guo, Y., Zhang, B. and D'inca, R. (2016) Dietary live yeast and mannan-oligosaccharide supplementation attenuate intestinal inflammation and barrier dysfunction induced by Escherichia coli in broilers. Br. J. Nutr., 116(11): 1878-1888.

49. Tan, J., Liu, S., Guo, Y., Applegate, T.J. and Eicher, S.D. (2014) Dietary L-arginine supplementation attenuates lipopolysaccharide-induced inflammatory response in broiler chickens. Br. J. Nutr., 111(8): 1394-1404.

50. Gadde, U.D., Oh, S., Lee, Y., Davis, E., Zimmerman, N., Rehberger, T. and Lillehoj, H.S. (2017) Dietary Bacillus subtilis-based direct-fed microbials alleviate LPS-induced intestinal immunological stress and improve intestinal barrier gene expression in commercial broiler chickens. Res. Vet. Sci., 114: 236-243.

51. Abd-El Rhman Shawkat, L., Fararh, K.M. and Fari, A.S. (2018) Effect of probiotics and chelated zinc on E. coli infected broilers. Benha Vet. Med. J., 35(2): 510-525.I 